Tor Sewring and Hans Theliander*

\title{
Acid precipitation of kraft lignin from aqueous solutions: the influence of anionic specificity and concentration level of the salt
}

https://doi.org/10.1515/hf-2018-0302

Received December 18, 2018; accepted April 2, 2019; previously published online May 22, 2019

Abstract: In this study, the formation of particles and evolution of the particle size distribution in the micron range were monitored in situ during acid precipitation of kraft lignin. The objective of this work was to study the influence of anionic specificity and the ion concentration level. The concentrations of ions in the solution were altered both in terms of the concentration of $\mathrm{Na}^{+}$and the type of anion in the salt added $\left(\mathrm{SO}_{4}^{2-}\right.$ and $\left.\mathrm{Cl}^{-}\right)$. The results indicate that a salting-out phenomenon occurred as $\mathrm{NaCl}$ was added ( $\mathrm{Na}^{+} \geq 2 \mathrm{~mol} \mathrm{~kg}^{-1}$ water) to the kraft lignin solution at high $\mathrm{pH}$, but not when $\mathrm{Na}_{2} \mathrm{SO}$, was added. However, the onset $\mathrm{pH}$ of the formation of particles $(\geq 1 \mu \mathrm{m})$, triggered by acidification, showed to be virtually non-specific to the anion but strongly dependent on the $\mathrm{Na}^{+}$concentration. As the $\mathrm{pH}$ decreased further to below the onset $\mathrm{pH}$ of the formation of particles $\geq 1 \mu \mathrm{m}$, the chord length distributions (particle-size related) indicated that most of the volume of the precipitated kraft lignin (and thus possibly also the mass) may be found among the micron-sized particles, despite the fact that a relatively large number of submicron particles may also be present. The volumebased distributions tended to be wide at relatively low $\mathrm{pH}$ and high $\mathrm{Na}^{+}$concentrations (e.g. pH 9.4 and $2.0 \mathrm{~mol} \mathrm{~kg}^{-1}$ water).

Keywords: anionic specificity, kraft lignin precipitation, particle size distribution

\footnotetext{
*Corresponding author: Hans Theliander, Forest Products and Chemical Engineering, Department of Chemistry and Chemical Engineering, Chalmers University of Technology, SE-412 96 Gothenburg, Sweden; and Wallenberg Wood Science Centre, Chalmers University of Technology/Royal Institute of Technology, Kemigården 4, SE-412 96 Gothenburg, Sweden, e-mail: hanst@chalmers.se

Tor Sewring: Forest Products and Chemical Engineering, Department of Chemistry and Chemical Engineering, Chalmers University of Technology, SE-412 96 Gothenburg, Sweden; and Wallenberg Wood Science Centre, Chalmers University of Technology/Royal Institute of Technology, Kemigården 4, SE-412 96 Gothenburg, Sweden
}

\section{Introduction}

The extraction of lignin from black liquor is an efficient way of increasing the material yield of the kraft pulp mill. One of the steps in the extraction process is the precipitation of kraft lignin from black liquor. The solubility of kraft lignin is essential in the precipitation stage of the extraction process, but it is also an important property in several parts of the integrated kraft pulp mill and biorefinery. An enhanced understanding of the mechanisms governing the precipitation of kraft lignin is required in order to improve control over the precipitation yield and properties of the kraft lignin retrieved.

To date, most of the studies found in the literature (Norgren et al. 2001a, 2002; Fritz et al. 2017) focusing on the phase behavior of kraft lignin have been conducted in dilute solutions at concentrations of salt and lignin of up to about $1 \mathrm{~mol} \mathrm{dm}^{-3}$ and $3 \mathrm{~g} \mathrm{dm}^{-3}$, respectively. At these conditions, it has been suggested that electrostatics has a significant impact on the phase behavior of kraft lignin (Norgren et al. 2001a). Results reported in the literature have also shown that the kinetics of the precipitation is influenced by the composition of the ionic species in the solution, i.e. display ion-specific effects (Norgren et al. 2002; Norgren and Mackin 2009).

It has been demonstrated that the dispersion stability of kraft lignin is affected by the anionic specificity according to the direct order of the Hofmeister series (Parsons et al. 2011; Schwierz et al. 2013): the ability to salt out kraft lignin was found to be ordered as $\mathrm{Cl}^{-}>\mathrm{Br}^{-}>\mathrm{NO}_{3}^{-}$, having $\mathrm{Na}^{+}$as the cation (Norgren et al. 2002). Moreover, a comparison of the dispersion stability has been made when alternating the anion between $\mathrm{SO}_{4}^{2-}$ and $\mathrm{Cl}^{-}$whilst keeping $\mathrm{Na}^{+}$as the cation in the added salt: the former was found to salt out the kraft lignin more efficiently than the latter, at the $\mathrm{Na}^{+}$concentrations and ionic strengths investigated (up to about $1.5 \mathrm{~mol}$ $\mathrm{dm}^{-3}$ for both parameters) (Norgren and Mackin 2009). In kraft cook experiments, however, the delignification of the wood tissue, at $\mathrm{Na}^{+}$concentrations up to $2 \mathrm{~mol} \mathrm{~kg}^{-1}$ water, was found to be lower for $\mathrm{Cl}^{-}$-rich cooking liquors than for the $\mathrm{SO}_{4}^{2-}$-rich counterparts (Bogren et al. 2009): 
this may be due to ion-specific effects affecting the solubility of kraft lignin.

Black liquors used in the precipitation stage of a lignin extraction process have rather high concentrations of both kraft lignin and inorganic ions: the total dry contents of liquids withdrawn from the evaporation train for lignin extraction may be as high as 30-40 wt $\%$, of which lignin may account for approximately a third. Parameters such as $\mathrm{pH}$, salt concentration, temperature and molecular properties of the kraft lignin have been shown to influence the yield of precipitation (Zhu and Theliander 2015; Zhu et al. 2015, 2016). Moreover, rather recent results indicate that the influence of $\mathrm{pH}$ and salt concentration on the formation of micron-sized particles remains high, even at high salt concentrations $\left(2-4 \mathrm{~mol} \mathrm{dm}^{-3}\right.$ ) (Sewring and Theliander 2018).

Knowledge of the influence of anion specificity at high concentrations of ions typical for concentrated black liquors is currently scarce. This study aims at exploring the ion-specific effects of $\mathrm{SO}_{4}^{2-}$ and $\mathrm{Cl}^{-}$on the precipitation process of kraft lignin in a rather wide range of $\mathrm{Na}^{+}$ concentration levels, i.e. $1.0-5.8 \mathrm{~mol} \mathrm{Na}^{+} \mathrm{kg}^{-1}$ water, with either $\mathrm{SO}_{4}^{2-}$ or $\mathrm{Cl}^{-}$as the anion in the added salt. The conditions at which the onset of the formation of micronsized particles starts to occur have been investigated in particular, along with the evolution of the particle size distribution of micron-particles as the suspension is acidified further, beyond the onset point for particles $\geq 1 \mu \mathrm{m}$. This study may therefore also address the question as to which sizes are most prevalent for micron-sized particles and, consequently, which size range of particles may be expected to carry most of the mass of the precipitated kraft lignin.

\section{Materials and methods}

Materials and experimental set-up: In this study, kraft lignin was precipitated from prepared aqueous solutions by means of acidification at predetermined levels of added salt and constant temperature $\left(65^{\circ} \mathrm{C}\right)$. The source of kraft lignin was a softwood LignoBoost ${ }^{\mathrm{TM}}$ lignin from a Nordic pulp mill, retrieved from the same batch utilized in a previous study (Sewring and Theliander 2018). The set-up was also the same as in this earlier study, i.e. experiments were conducted in a baffled vessel, of volume $0.5 \mathrm{dm}^{3}$, equipped with a pitch-blade impeller (with an impeller-to-vessel diameter ratio of 0.5 ), but the agitation rate in the present study was kept constant at $250 \mathrm{rpm}$. The temperature was controlled via indirect heating by connecting a heated oil bath to the jacket of the precipitation vessel.

The experimental solutions were prepared by dissolution of the kraft lignin powder at a $\mathrm{NaOH}$ (purity $\geq 98 \%$, Sigma Aldrich, Stockholm, Sweden) concentration of $1.0 \mathrm{~mol} \mathrm{~kg}^{-1}$ water followed by dilution to a concentration of $0.5 \mathrm{~mol} \mathrm{Na}^{+} \mathrm{kg}^{-1}$ water. Deionized water was used throughout all experiments. The initial sodium content of the lignin powder was determined in a previous study to be $0.16 \mathrm{wt} \%$ (Sewring et al. 2019). The solutions were pre-filtered (using a $0.45-\mu \mathrm{m}$ pore size Sartorius stedim filter Type 184, regenerated cellulose) prior to the experiments in order to remove non-soluble material: $<1.6 \mathrm{wt} \%$ of the original kraft lignin powder was removed in this operation. The final concentration of the kraft lignin was 0.1 $\mathrm{kg}$ lignin $\mathrm{kg}^{-1}$ water and its initial $\mathrm{pH}$ was measured as being in the range $12.2-12.3$ at $25^{\circ} \mathrm{C}$. All other $\mathrm{pH}$ measurements in this study were also made at about $25^{\circ} \mathrm{C}$ using a Mettler Toledo SevenCompact ${ }^{\mathrm{TM}}$ S220 pH-meter (Greifensee, Switzerland) with automatic temperature correction and an InLab Max Pro-ISM pH electrode calibrated at room temperature. At the start of the experiments, prior to acidification, either $\mathrm{Na}_{2} \mathrm{SO}_{4}$ (purity $>99.5 \%$, Fisher Chemical, Loughborough, UK) or $\mathrm{NaCl}$ (purity $\geq 99.5 \%$, Sigma Aldrich, Söborg, Denmark) was added to the prepared solutions in order to reach the target concentration of $\mathrm{Na}^{+}$ions while monitoring in situ the formation of particles $\geq 1 \mu \mathrm{m}$. In order to ensure the presence of the same type of anion throughout each experiment, the choice of acid for the acidification was based on the type of anion in the added salt: $\mathrm{H}_{2} \mathrm{SO}_{4}$ was used if $\mathrm{Na}_{2} \mathrm{SO}_{4}$ was added and $\mathrm{HCl}$ if $\mathrm{NaCl}$ was added. The acidification was made drop-wise in sequences during the experiments to allow local $\mathrm{pH}$ gradients in the liquid to even out. The conditions of the experiments conducted are outlined in Table 1, which shows both the $\mathrm{Na}^{+}$concentration (mol kg-1 water) and the ionic strength (mol kg-1 water) in each experiment, where the latter is calculated as follows:

$$
\text { ionic strength }=0.5 \sum_{i} z_{i}^{2} m_{i}
$$

where $z_{i}$ and $m_{i}$ are the valency and molality, respectively, of an ion, $i$. When the kraft lignin is added to the $1.0 \mathrm{~mol} \mathrm{~kg}^{-1}$ water $\mathrm{NaOH}$ solution, some of the $\mathrm{HO}^{-}$ions will be consumed in the deprotonation reaction of the ionizable groups on the kraft lignin. The contents of the phenolic and carboxylic groups on the kraft lignin used in this study have been quantified elsewhere to 4.27 and $0.45 \mathrm{~mol} \mathrm{~kg}^{-1}$ lignin, respectively (Aminzadeh et al. 2018). Determination of the ionic

Table 1: Conditions of the experiments conducted.

\begin{tabular}{lrrl}
\hline Experiment ID & $\begin{array}{r}\text { Na+ conc. } \\
\left(\mathrm{mol} \mathrm{kg}^{-1} \text { water) }\right.\end{array}$ & $\begin{array}{r}\text { Ionic strength } \\
\left(\mathrm{mol} \mathrm{kg}^{-1} \text { water) }\right.\end{array}$ & $\begin{array}{l}\text { Anion } \\
\text { added }\end{array}$ \\
\hline Experiment 1 & 4.0 & 5.7 & $\mathrm{SO}_{4}^{2-}$ \\
Experiment 2 & 2.0 & 2.8 & $\mathrm{SO}_{4}^{2-}$ \\
Experiment 3 & 1.0 & 1.3 & $\mathrm{SO}_{4}^{2-}$ \\
Experiment 4 & 3.9 & 3.9 & $\mathrm{Cl}^{-}$ \\
Experiment 5 & 2.0 & 2.0 & $\mathrm{Cl}^{-}$ \\
Experiment 6 & 1.0 & 1.0 & $\mathrm{Cl}^{-}$ \\
Experiment 7 & 5.7 & 5.7 & $\mathrm{Cl}^{-}$ \\
Experiment 8 & 2.7 & 2.7 & $\mathrm{Cl}^{-}$ \\
Experiment 9 & 1.2 & 1.2 & $\mathrm{Cl}^{-}$ \\
Experiment 10 & 4.0 & 4.0 & $\mathrm{Cl}^{-}$ \\
\hline
\end{tabular}

aBased on the inorganic ions in the liquid. Equation 1 was used

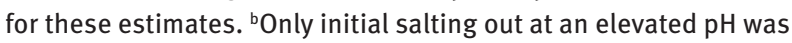
studied: $\mathrm{NaCl}$ corresponding to $3.0 \mathrm{~mol} \mathrm{~kg}^{-1}$ water was added to the kraft lignin solution, which was prepared from $1.0 \mathrm{~mol} \mathrm{NaOH} \mathrm{kg}{ }^{-1}$ water. 
strength was based on the original concentration of the $\mathrm{NaOH}$ in the prepared solutions (i.e. as $0.5 \mathrm{~mol} \mathrm{~kg}^{-1}$ water in all but one case) before acidification, including the added salt, even though the $\mathrm{HO}^{-}$ ions react, to some extent, with the ionizable groups on the kraft lignin added to the solution during its dissolution process. Regardless of this, the amount of negative charges will remain the same: some of the electric charges carried by the $\mathrm{HO}^{-}$ions are merely transferred to the kraft lignin by means of the equilibrium reactions of deprotonation. It can be noted here that that Experiments 1-3 match Experiments 7-9 with respect to ionic strength whilst the anion type is altered. This allows the dependency of the precipitation behavior on both the $\mathrm{Na}^{+}$concentration and ionic strength to be examined, as well as whether the type of anion matters or not, at various levels of either $\mathrm{Na}^{+}$concentration or ionic strength. The solubility of $\mathrm{NaCl}$ and $\mathrm{Na}_{2} \mathrm{SO}_{4}$ in water are approximately 6.1 and $3.2 \mathrm{~mol} \mathrm{~kg}^{-1}$ water at $65^{\circ} \mathrm{C}$, respectively (Bharmoria et al. 2012, 2014). Even though the salt concentrations are rather high in the experiments, they are all significantly below the solubility limits except in the case of Experiment 7, with an $\mathrm{NaCl}$ concentration of $5.2 \mathrm{~mol} \mathrm{~kg}^{-1}$ water: not only is this rather close to the solubility limit, it also had an additional $0.5 \mathrm{~mol}$ $\mathrm{Na}^{+} \mathrm{kg}^{-1}$ water from the added $\mathrm{NaOH}$. The highest concentration of $\mathrm{Na}_{2} \mathrm{SO}_{4}$ in the experiments was $1.8 \mathrm{~mol} \mathrm{~kg}^{-1}$ water.

The formation of particles was monitored in situ by a focused beam reflectance measurement $\left(\mathrm{FBRM}^{\circledR}\right)$ unit of model G400 (Mettler Toledo). It measures the chord lengths of particles and reports the chord length distribution in the size range of $1-1000 \mu \mathrm{m}$. With its probe tip emerged in liquid, this laser-based technique detects the backscattered light as particles cross the circular path of the focal point of the laser that scans the liquid as an experiment proceeds. Thus, the changes in chord length distribution that occur during the progress of precipitation can be monitored in situ. The chord length distribution is related to the particle size distribution (Wynn 2003; Pandit and Ranade 2016), although its interpretation may depend on the characteristic shape of the particles being considered.

The chord length distribution is reported by the instrument as counts $\left(\# \mathrm{~s}^{-1}\right)$ of the various classes of chord lengths that have been measured. When the chord lengths are being measured during an experiment, they are distributed by the equipment's software according to a predefined set of chord length classes or "bins": in this study, the predefined setting named "primary particles" was used. This allocation procedure defines the bin edges according to a geometric series that results in the classes subsequently having broader chord length intervals, i.e. the widths of the chord length intervals increase along the chord length dimension. This setting has the advantage that, if relatively small particles are expected, it gives a higher resolution of the distribution in the interval of small particles.

Analysis of chord length distributions: Previous investigations of the precipitation of kraft lignin (Sewring and Theliander 2018) using the distribution setting mentioned earlier found that the mode values obtained from the chord length distributions are often located in the size range of about 1-20 $\mu \mathrm{m}$. However, the increasingly finer resolution of the chord length axis toward the lower limit of $1 \mu \mathrm{m}$ makes it all the more difficult to compare the relative abundance of classes over a larger size interval and, in particular, to make judgments of how the relative amount of submicron-sized particles, which are not monitored, may compare to the micron-sized particles that are monitored. This issue was addressed by redefining the chord length classes with more equidistant class edges: the counts were redistributed in such a way that the width of each class was approximately 5 and $10 \mu \mathrm{m}$ in the number and volume-based distributions, respectively. The accuracy of the redistributions was satisfactory up to about $30 \mu \mathrm{m}$, after which deviations from the targets in the class-width were virtually apparent (see the chord length axis in Figure 7 in the Results section). This redistribution provides an opportunity to obtain an idea of the occurrence of particles in the unmonitored submicron regime based on the shape of the distribution obtained in the micron range.

The number-based distribution may, moreover, be complemented with a volume-based distribution to depict which particle classes in the micron range contribute the most to the volume of the precipitated lignin. It may also provide information on the relative changes in the total volume of particles in the micron range as the solution conditions are altered. However, in order to conduct such an analysis, a few important assumptions have to be made as follows:

- The particles formed are spherical.

- The chord lengths measured correspond to the diameters of spheres.

- $\quad$ The densities of the particles are equal.

The volume fraction (volume \%), of a specific class of particles, i.e. belonging to a given size interval, may then be expressed as follows:

$$
\text { vol. } \%\left(d_{i_{1}} \leq d_{i} \leq d_{i_{2}}\right)=100\left(\sum_{i=i_{1}}^{i_{2}} d_{i}^{3} N_{i}\right)\left(\sum_{i=1}^{i_{\max }} d_{i}^{3} N_{i}\right)^{-1}
$$

where $i_{1}$ and $i_{2}$ are the indices of the smallest and the largest chord lengths, $d_{i}$, of the specific size-class considered, $i_{\max }$ is the index of the largest chord length considered in the whole distribution, and $N_{i}$ is the count of the specific chord length, $d_{i}$.

\section{Results and discussion}

\section{The course of precipitation}

Figures 1-4 show the course of precipitation as salt and acid were added at various $\mathrm{Na}^{+}$concentration levels and types of anion in the added salt. Generally, a peak in counts can be seen shortly after acid has been added. This is most probably due to lignin agglomerates being formed temporarily in an environment that was locally very acidic, i.e. where the acid was added. Such local spots in the liquid are not in equilibrium with the bulk; so, as the $\mathrm{pH}$ is evened out, the particles that are formed disintegrate again. This observation has also been made in earlier investigations (Sewring and Theliander 2018).

A peak also appeared after the salt was added, although it may be due to particles of both salt and lignin. In the case at $3.9 \mathrm{~mol} \mathrm{Na} \mathrm{kg}^{-1}$ water after adding $\mathrm{NaCl}$, it can be observed in Figure 1 that the count levels did not return to the baseline level after the salt addition, but remained stable at a certain level instead. This is most likely lignin particles that were formed: a reference test conducted at similar conditions, but omitting lignin, showed that the 

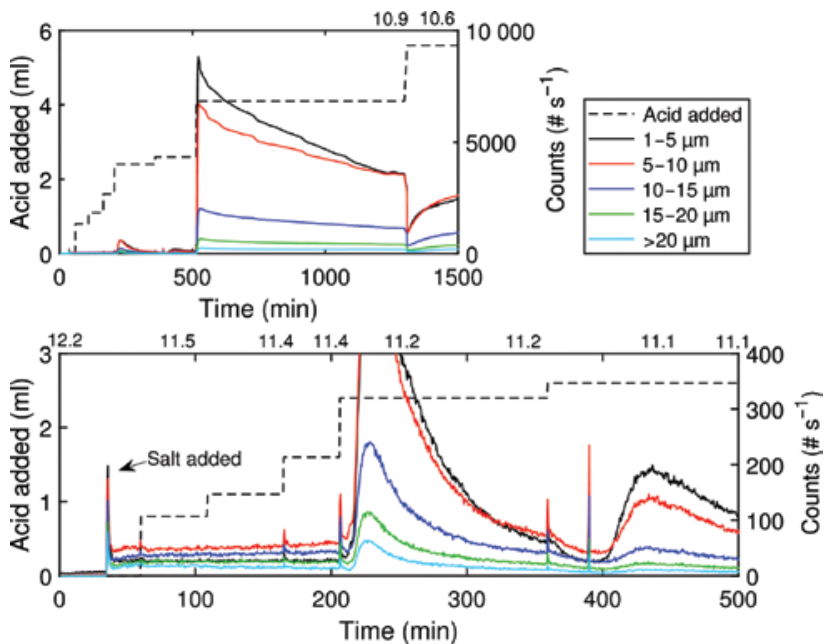

Figure 1: Count levels of the chord length classes at various points in time during Experiment 4.

System: $3.9 \mathrm{~mol} \mathrm{Na}^{+} \mathrm{kg}^{-1}$ water and $\mathrm{Cl}^{-}$as the anion in added salt. Above: full experiment. Below: early stage of precipitation. The horizontal lines of values above each graph display the $\mathrm{pH}\left(25^{\circ} \mathrm{C}\right)$ measured on various occasions during the experiment.
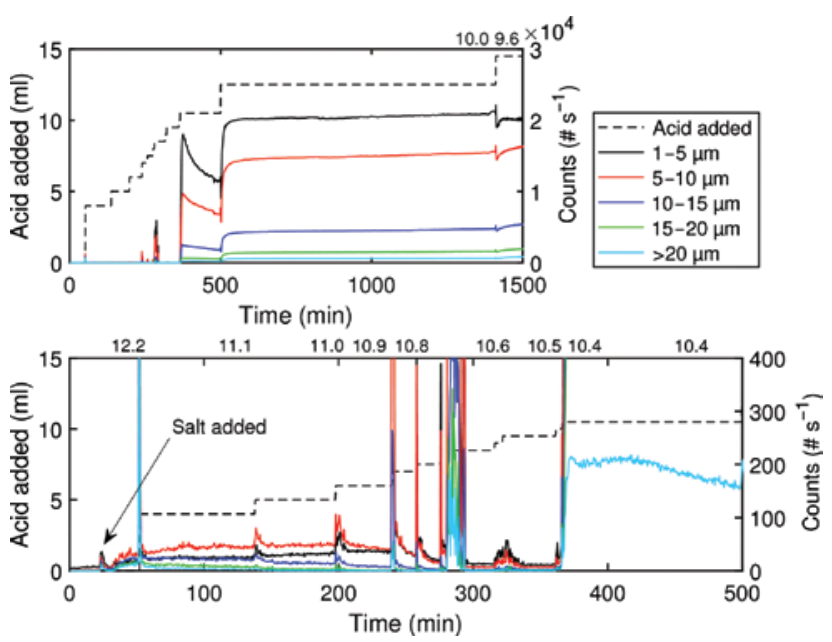

Figure 2: Count levels of the chord length classes at various points in time during Experiment 5.

System: $2.0 \mathrm{~mol} \mathrm{Na}^{+} \mathrm{kg}^{-1}$ water and $\mathrm{Cl}^{-}$as the anion in added salt. Above: full experiment. Below: early stage of precipitation. The horizontal lines of values above each graph display the $\mathrm{pH}\left(25^{\circ} \mathrm{C}\right)$ measured on various occasions during the experiment.

count levels returned quickly to the baseline after the salt peak had appeared. A behavior similar to that in Figure 1 can also be seen in Figure 2, where the concentration is $2.0 \mathrm{~mol} \mathrm{Na}^{+} \mathrm{kg}^{-1}$ water and $\mathrm{NaCl}$ is also the added salt. Different observations can be made in the cases with added $\mathrm{Na}_{2} \mathrm{SO}_{4}$ : the count levels return to the baseline levels after the salt addition, both at 4.0 and $2.0 \mathrm{~mol} \mathrm{Na}^{+} \mathrm{kg}^{-1}$ water (Figures 3 and 4, respectively), although the formation of
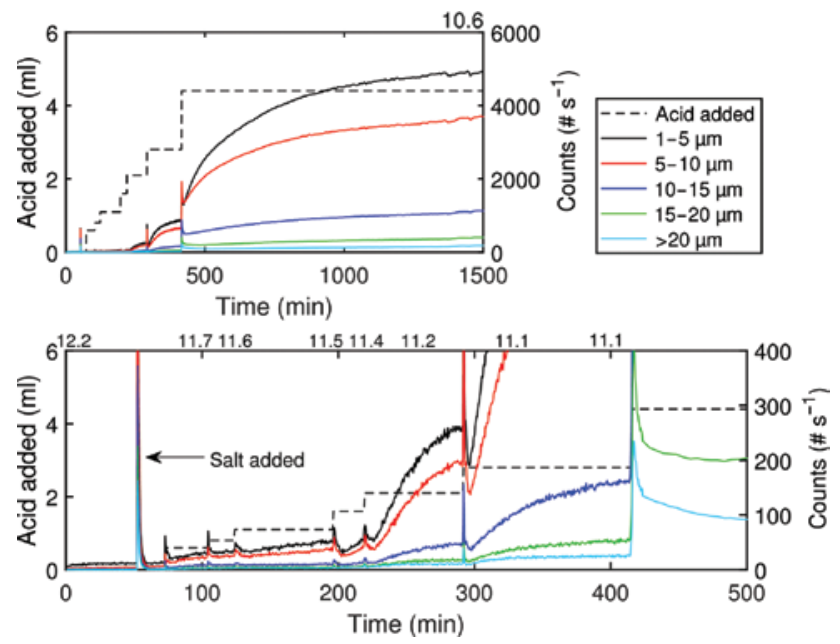

Figure 3: Count levels of the chord length classes at various points in time during Experiment 1.

System: $4.0 \mathrm{~mol} \mathrm{Na} \mathrm{kg}^{-1}$ water and $\mathrm{SO}_{4}^{2-}$ as the anion in added salt. Above: full experiment. Below: early stage of precipitation. The horizontal lines of values above each graph display the $\mathrm{pH}\left(25^{\circ} \mathrm{C}\right)$ measured on various occasions during the experiment.
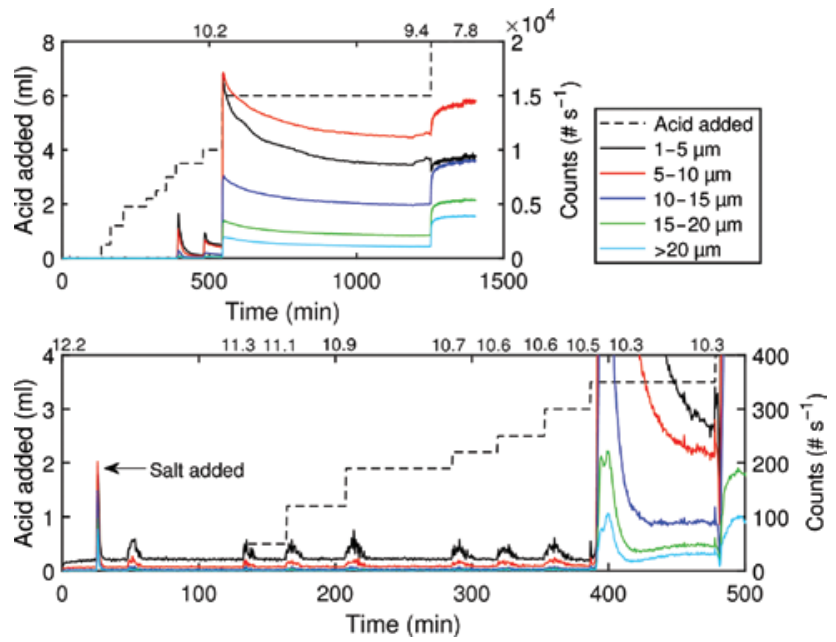

Figure 4: Count levels of the chord length classes at various points in time during Experiment 2.

System: 2.0 mol Na$~ \mathrm{~kg}^{-1}$ water and $\mathrm{SO}_{4}^{2-}$ as the anion in added salt. Above: full experiment. Below: early stage of precipitation. The horizontal lines of values above each graph display the $\mathrm{pH}\left(25^{\circ} \mathrm{C}\right)$ measured on various occasions during the experiment.

micron-sized particles due to a relatively minor decrease in the $\mathrm{pH}$ at the higher concentration level (Figure 3), which is a result of acidification, was observed. This suggests that the system may have been rather close to forming micron-sized particles already after the salt addition. It is important to note that only particles $\geq 1 \mu \mathrm{m}$ are detected, which implies that stable submicron particles, not reported by the instrument, may have been formed at 
the initial $\mathrm{pH}$ (about 12.3) at both 4.0 and $2.0 \mathrm{~mol} \mathrm{Na}^{+} \mathrm{kg}^{-1}$ water for the cases in which $\mathrm{Na}_{2} \mathrm{SO}_{4}$ was added.

After the salt had been added the general outcome was that, with the exception of Experiment 1 (Figure 3), virtually no increase in counts could be observed initially as the acid was subsequently added. Not until a certain point was reached, referred to here as "the onset of the formation of particles $\geq 1 \mu \mathrm{m}$ due to acidification", could the formation of a significant quantity of particles be observed due to the $\mathrm{pH}$ being lowered sufficiently. Irrespective of the type of anion in the added salt, this occurred at about $\mathrm{pH} 11.3$ and $\mathrm{pH} 10.4$ at the $\mathrm{Na}^{+}$concentration levels of $4 \mathrm{~mol} \mathrm{~kg}^{-1}$ water and $2 \mathrm{~mol} \mathrm{~kg}^{-1}$ water, respectively. A minor and slow increase in the count level, as discussed earlier, could be observed between $\mathrm{pH} 11.4$ and 11.7 at $4.0 \mathrm{~mol} \mathrm{~kg}^{-1}$ in the case of $\mathrm{SO}_{4}^{2-}$, but this behavior is quite different from the quite drastic response of the system at $\mathrm{pH}$ 11.3, when the liquid was subjected to further acidification. Thus, the aforementioned observations may indicate ionspecific effects in the early stage of precipitation, depending on whether $\mathrm{SO}_{4}^{2-}$ or $\mathrm{Cl}^{-}$was present in the salt added. This is discussed further in the section on "The onset of precipitation".

Below pH 11, after a considerable amount of acid had been added, the count levels increased significantly. The kinetics of the particle formation is rather different in Figure 3 compared to the other three cases, shown in Figures 1, 2 and 4: in Figure 3, the particle formation was slow and steady as opposed to the other cases, where it was much faster and resulted in unstable particles (see the decrease in count levels after a rapid increase). The difference in the kinetics of particle formation is probably due to both the specific anion-type and the concentration, e.g. the characteristics of the kinetics differ for the two concentration levels in the $\mathrm{SO}_{4}^{2-}$-case (c.f. Figures 3 and 4). Further investigation of the mechanisms behind these differences is necessary.

\section{The onset of precipitation}

Figure 5 shows the onset of the formation of stable particles $\geq 1 \mu \mathrm{m}$ due to acidification as a function of the $\mathrm{Na}^{+}$ concentration. The uncertainty in the measurement of the onset $\mathrm{pH}$ is about $0.1 \mathrm{pH}$ units: it is clear that the type of anion does not have an important influence, if any at all, on the onset. Instead, the most significant observation is that the onset $\mathrm{pH}$ was found to be strongly dependent on the $\mathrm{Na}^{+}$concentration, i.e. the counterion concentration that screens the negative charges on the kraft lignin macromolecules and particles. The largest dependence was found at low $\mathrm{Na}^{+}$concentrations, decreasing as the $\mathrm{Na}^{+}$concentration was increased: at about $4 \mathrm{~mol} \mathrm{Na}{ }^{+} \cdot \mathrm{kg}^{-1}$ water, the influence of the increased concentration of the added salt $(\mathrm{NaCl})$ leveled out, which is in agreement with an earlier study (Sewring and Theliander 2018).

As mentioned previously, when $\mathrm{NaCl}$ was added to reach the target concentration of the salt at the initial $\mathrm{pH}$ 12.2-12.3, the FBRM result indicated that a small quantity of particles had been formed at $\mathrm{Na}^{+}$concentrations of $2 \mathrm{~mol} \mathrm{~kg}^{-1}$ water or higher. At an elevated $\mathrm{pH}$ ( $\mathrm{pH}$ 13.4), i.e. in Experiment 10, some parts of the kraft lignin were also observed to be salted out at $4.0 \mathrm{~mol} \mathrm{Na}{ }^{+} \mathrm{kg}^{-1}$ water with $\mathrm{NaCl}$ : this shows that increasing the $\mathrm{pH}$ from $\mathrm{pH} 12.2$ to 13.4 could not prevent the salting out phenomenon. When acid was subsequently added, no further increase in the amount of micron-sized particles formed was observed until the onset $\mathrm{pH}$ was reached. There is obviously a part of the kraft lignin that precipitates, forming micron-sized particles, specifically by means of added $\mathrm{NaCl}$ at the initial $\mathrm{pH}$ (12.2-12.3), i.e. salted out. The remaining part precipitates after the $\mathrm{pH}$ has been lowered sufficiently to a certain level, observed as the "onset $\mathrm{pH}$ due to acidification"; a possible explanation is presented later in this section.

A previous comparison made between the salting-out ability of $\mathrm{Cl}^{-}$and $\mathrm{SO}_{4}^{2-}$ showed that the latter was more potent in the range of concentrations investigated: up to about $1.5 \mathrm{M} \mathrm{Na}^{+}$(Norgren and Mackin 2009). In this study, on the other hand, the onset $\mathrm{pH}$ due to acidification was found to be virtually the same for the two types of salts in the concentration range investigated; in fact, for a small fraction of the kraft lignin, the opposite relation was

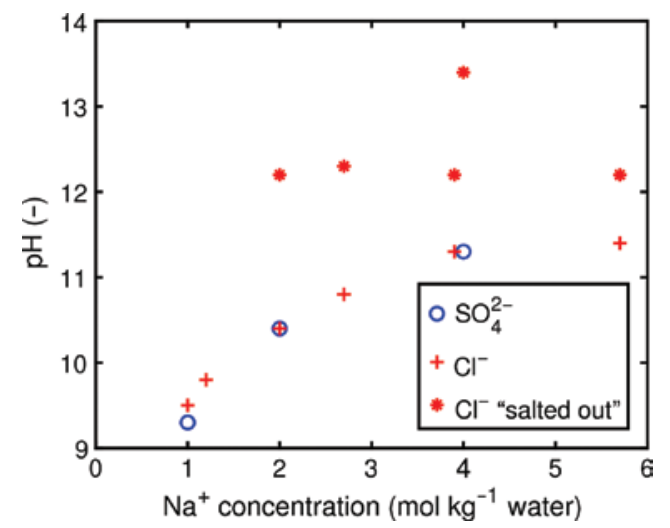

Figure 5: The $\mathrm{pH}$ value $\left(25^{\circ} \mathrm{C}\right)$ at the onset of the formation of particles $(\geq 1 \mu \mathrm{m})$, after subsequent addition of acid, at various $\mathrm{Na}^{+}$ ion concentration levels and types of anion (red crosses and blue circles).

Red stars: observations of small amounts of kraft particles formed when salt was added, referred to as being "salted out". 
found in terms of the micron-sized particles formed due to added salt, considering the specific salting-out phenomenon for $\mathrm{NaCl}$ at $\mathrm{Na}^{+}$concentrations $\geq 2 \mathrm{~mol} \mathrm{~kg}^{-1}$ water at high $\mathrm{pH}$ values of about $\mathrm{pH}$ 12.2. However, it should be kept in mind that those two studies may not necessarily be directly comparable, as the focus on particle formation was placed on different length-scales and in different concentration ranges: the former was on the submicron level, concentrating on the formation of stable nuclei and primary particles at dilute lignin concentrations, whilst the latter was on the micron level at non-dilute lignin concentrations, as well as at intervals of salt concentrations shifted to higher values. Moreover, Hofmeister effects have shown to be concentration-dependent and may even reverse when the concentration level of the salt moves from low to high (Zhang and Cremer 2009). Consequently, further investigation is suggested to bring clarity to the ion-specific precipitation behaviors observed with respect to the type of anions $\mathrm{Cl}^{-}$and $\mathrm{SO}_{4}^{2-}$ used.

It is possible that kraft lignin of high molecular weight precipitates at $\mathrm{Na}^{+}$concentration levels of $2 \mathrm{~mol} \mathrm{~kg}^{-1}$ water or higher, even at rather high $\mathrm{pH}(>12)$ and, perhaps more specifically, that it also forms micron-sized particles when $\mathrm{Cl}^{-}$is the dominating anion. The high-molecular-weight kraft lignins may behave like charged colloids, the dispersion stability of which may be governed by electrostatic repulsion to a large extent and, consequently, they become sensitive to having their charged groups screened by counterions. Kraft lignins of lower molecular weight may, on the other hand, be gradually more difficult to precipitate because they require increased salt concentration levels and/or lower $\mathrm{pH}$ levels to precipitate, according to previous investigations (Norgren et al. 2001b, 2002; Zhu et al. 2016). At the far end of the molecular weight spectrum, the fragments of kraft lignin may be viewed, more or less, as large ions carrying only one or a few charges. In order to precipitate this fraction, even at very high salt concentration levels, the phenolic groups have to be essentially protonated. This may explain the changes observed in the precipitation yield and particle size distributions that still occur in the range of $2-4 \mathrm{~mol} \mathrm{~kg}^{-1}$ water of salt as the $\mathrm{pH}$ changes close to values where the $\mathrm{p} K_{\mathrm{a}}$ of the phenolic groups can be expected to be found [see (Norgren and Lindström 2000; Zhu and Theliander 2015; Zhu et al. 2015, 2016) and this work]. The apparent $\mathrm{p} K_{\mathrm{a}}$ value may vary to some degree with the salt concentration, as the screening of the negatively charged surface of the kraft lignin, which influences the apparent $\mathrm{p} K_{\mathrm{a}}$, depends on the salt concentration level (Norgren and Lindström 2000). Between the types of molecular kraft lignin characterized as being colloidal and "large ion", there may be a gradual cross-over between these two extremes that also exhibits significant differences in phase behavior.

The heterogeneity of the molecular properties may therefore play a significant role in the solubility of kraft lignin in a rather broad range of conditions with respect to $\mathrm{pH}$ and salt concentration and explain, at least to a significant degree, the observations found here and elsewhere (Zhu and Theliander 2015; Zhu et al. 2015, 2016; Sewring and Theliander 2018).

\section{Chord length distributions}

The changes in the amount of precipitated kraft lignin present in the form of micron-sized particles, at various $\mathrm{pH}$ and $\mathrm{Na}^{+}$concentration levels, are depicted in Figure 6. These changes are reflected in the total volume of particles measured per second $\left(\mu \mathrm{m}^{3} \mathrm{~s}^{-1}\right)$ by the FBRM unit, which may be obtained from the chord length distribution and by applying the assumptions given in the section "Analysis of chord length distributions". The trend is that, in general, a lower $\mathrm{pH}$ and/or a higher $\mathrm{Na}^{+}$concentration results in an increased volume, and hence probably also mass, of micron-sized particles.

The chord length distributions, both number-based (counts) and volume-based (vol. \%), are displayed in Figure 7 at the various conditions investigated. The countbased distributions illustrate the particle sizes that are most common, whereas the volume-based distributions indicate not only where most of the mass of the precipitated kraft lignin may potentially be found among the micron-sized particles, but also the relative changes in the distribution of mass among those particles as the condition

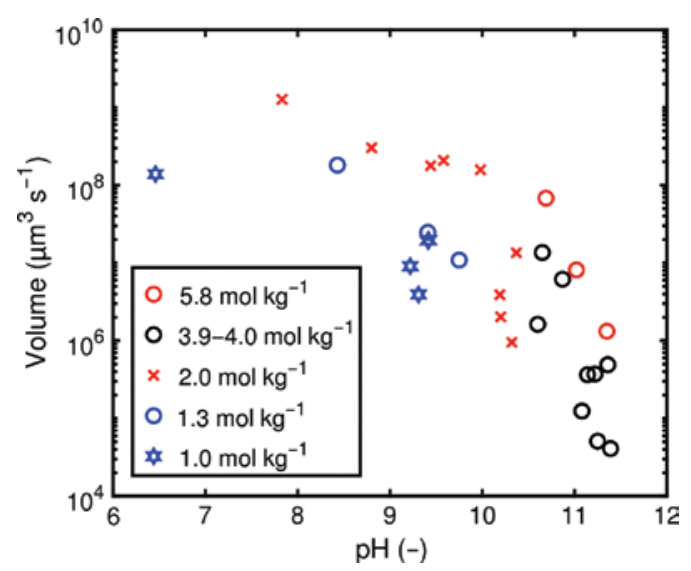

Figure 6: Total volume of particles measured by the FBRM probe per second vs. $\mathrm{pH}\left(25^{\circ} \mathrm{C}\right)$ at various $\mathrm{Na}^{+}$concentrations ( $\mathrm{mol} \mathrm{kg}^{-1}$ water). Each $\mathrm{Na}^{+}$concentration level contains data points with both $\mathrm{NaCl}$ and $\mathrm{Na}_{2} \mathrm{SO}_{4}$ as the added salt. 

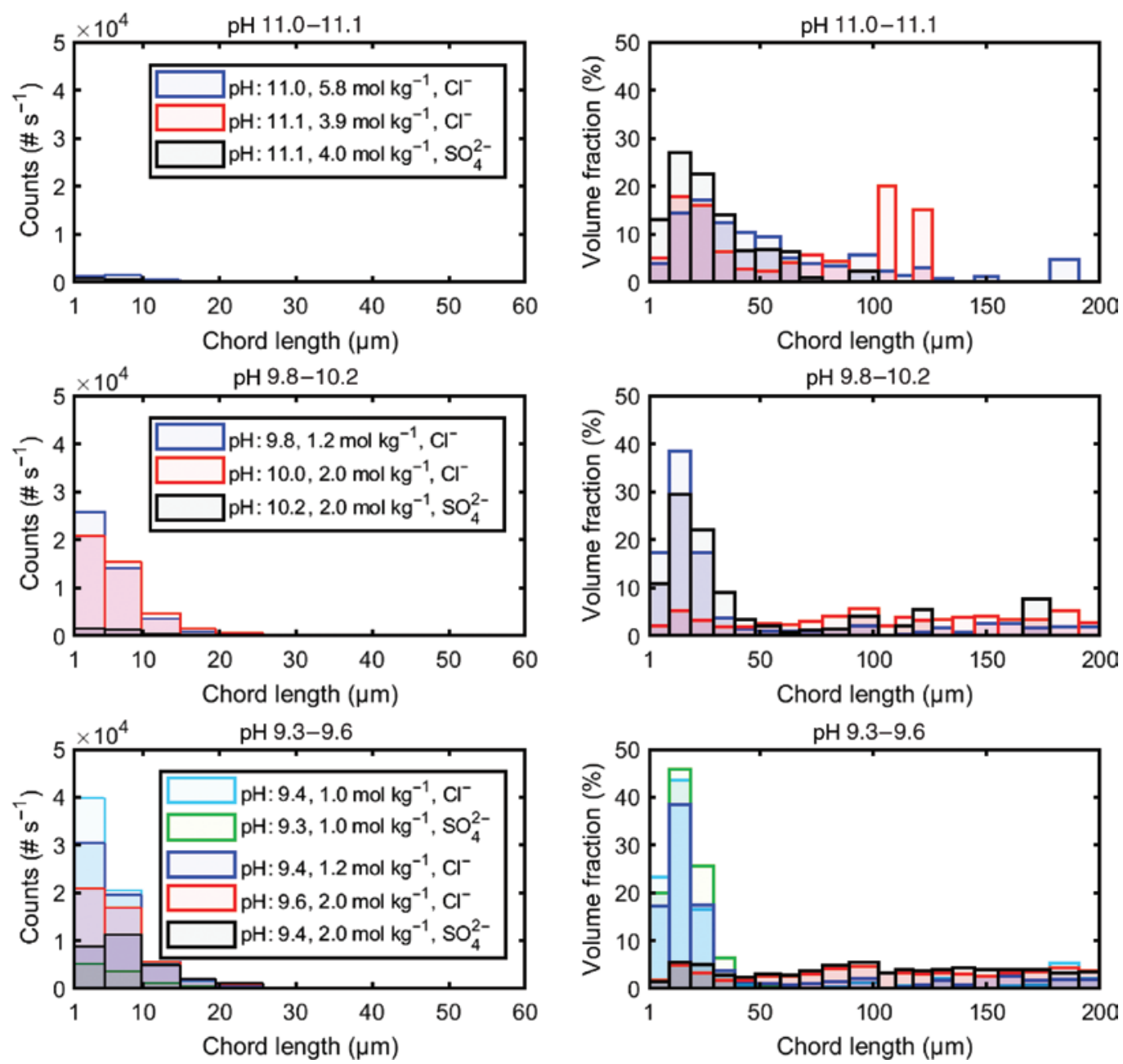

Figure 7: Chord length distributions at various $\mathrm{Na}^{+}$concentrations, $\mathrm{pH}$ levels $\left(25^{\circ} \mathrm{C}\right)$ and anion in the added salt. Left column: count-based. Right column: volume-based (volume fractions of the total volume of micron-sized particles). The count-based and volume-based diagrams are truncated at 60 and $200 \mu \mathrm{m}$, respectively. The vol. \% shown do not sum up to $100 \%$ at some conditions because particles $>200 \mu \mathrm{m}$ may make significant contributions to the total volume of particles.

in the system is varied. It ought to be mentioned, however, that such an analysis relies on the assumptions outlined in the "Analysis of chord length distribution" section.

At a given $\mathrm{pH}$ level, it can be observed that the higher the $\mathrm{Na}^{+}$concentration, the lower the count value of particles in the range of 1-5 $\mu \mathrm{m}$ (see the column on the lefthand side in Figure 7). The shift in the distribution at increased concentration levels of salt indicates that the abundance of micron-sized particles belonging to the fineparticle end of the distribution is decreased. Nevertheless, it is reasonable to assume that submicron particles exist as well, and possibly also in significant numbers judging by the shape of the number-based distributions: the particle population of $1-5 \mu \mathrm{m}$ is consistently the most abundant fraction of the micron-sized particles. In the case of an extremely high $\mathrm{Na}^{+}$concentration, e.g. $5.8 \mathrm{~mol} \mathrm{Na}^{+} \mathrm{kg}^{-1}$ water, it could in fact be observed that the mode value of the count-based distribution, i.e. the most common fraction of particles, was found in the size range of 5-10 $\mu \mathrm{m}$, even though it was rather close in count value to that of the 1-5 $\mu \mathrm{m}$ particle-class.

The volume-based distributions, found in the columns on the right-hand side in Figure 7, show that the mode value in the volume-based distribution is generally found at $10-20 \mu \mathrm{m}$, although, at $\mathrm{pH}$ levels around 10 or lower and at $\mathrm{Na}^{+}$concentrations of $2 \mathrm{~mol} \mathrm{~kg}^{-1}$ water or higher, the rather rare but large particles $(>100 \mu \mathrm{m})$ tend to dominate volume-wise. In such cases, the volumebased distributions are very wide, regardless of whether they are considered to be bimodal or monomodal. Taking into consideration the rapidly declining amount of particulate volume carried by smaller particles $(1-10 \mu \mathrm{m})$, it is 
realistic to expect that the mass of submicron particles is negligible, or at least small, compared to the mass of the micron-sized particles at the conditions investigated. The volume-based fraction of particles in the $1-10 \mu \mathrm{m}$ range is, for instance, around a mere $2 \%$ at $2.0 \mathrm{~mol} \mathrm{Na}^{+} \mathrm{kg}^{-1}$ water and $\mathrm{pH}$ 9.4. For such a distribution, it is a realistic possibility that most of the volume, and thus also the mass, of the precipitated lignin may be in the form of micron-sized particles.

\section{Conclusions}

The following conclusions could be drawn from this study:

- The onset of the formation of particles $(\geq 1 \mu \mathrm{m})$ due to acidification was shown to be independent of the type of anion in the added salt. Instead, it was strongly dependent on the concentration of $\mathrm{Na}^{+}$. The onset $\mathrm{pH}$ observed as a result of acidification varied in the range of 9.3-11.4 in the interval of $1.0-4.0 \mathrm{~mol} \mathrm{Na}^{+} \mathrm{kg}^{-1}$ water.

- The onset of the formation of particles $(\geq 1 \mu \mathrm{m})$ due to the addition of salt was found to be dependent on the type of anion present in the added salt, i.e. $\mathrm{SO}_{4}^{2-}$ or $\mathrm{Cl}^{-}$. In the case of $\mathrm{Cl}^{-}$, the formation of a relatively small amount of stable particles $(\geq 1 \mu \mathrm{m})$ was observed when the salt was added and reached a concentration of $2 \mathrm{~mol} \mathrm{Na}^{+} \mathrm{kg}^{-1}$ water or higher at a $\mathrm{pH}$ value of about 12.2-12.3, whereas this salting-out phenomenon was absent when $\mathrm{SO}_{4}^{2-}$ was used.

- Below the onset $\mathrm{pH}$, volumetric estimates based on the chord length distributions indicate that most of the volume of the precipitated kraft lignin could probably be found among the micron-sized particles. These estimates were based on three assumptions made about the particles: that they are all spherical, have equal density and the measured chord length represents their diameter. However, the distributions also indicated that a significant portion of the total number of particles may be submicron in size. At a given $\mathrm{pH}$ level, moreover, as the $\mathrm{Na}^{+}$concentration increased, the volume-based chord length distribution shifted in relative weight toward larger particles.

Author contributions: All the authors have accepted responsibility for the entire content of this submitted manuscript and approved submission.

Research funding: The Knut and Alice Wallenberg Foundation is thanked for the financial support received. Knut och Alice Wallenbergs Stiftelse, Funder Id: http://dx.doi. org/10.13039/501100004063, Grant Number: Wallenberg Wood Science Center.

Employment or leadership: None declared.

Honorarium: None declared.

\section{References}

Aminzadeh, S., Lauberts, M., Dobele, G., Ponomarenko, J., Mattsson, T., Lindström, M.E., Sevastyanova, O. (2018) Membrane filtration of kraft lignin: structural charactristics and antioxidant activity of the low-molecular-weight fraction. Ind. Crops Prod. 112:200-209.

Bharmoria, P., Gupta, H., Mohandas, V.P., Ghosh, P.K., Kumar, A. (2012) Temperature invariance of $\mathrm{NaCl}$ solubility in water: inferences from salt-water cluster behavior of $\mathrm{NaCl}, \mathrm{KCl}$, and $\mathrm{NH}_{4} \mathrm{Cl}$. J. Phys. Chem. B 116:11712-11719.

Bharmoria, P., Gehlot, P.S., Gupta, H., Kumar, A. (2014) Temperature-dependent solubility transition of $\mathrm{Na}_{2} \mathrm{SO}_{4}$ in water and the effect of $\mathrm{NaCl}$ therein: solution structures and salt water dynamics. J. Phys. Chem. B 118:12734-12742.

Bogren, J., Brelid, H., Bialik, M., Theliander, H. (2009) Impact of dissolved sodium salts on kraft cooking reactions. Holzforschung 63:226-231.

Fritz, C., Salas, C., Jameel, H., Rojas, O.J. (2017) Self-association and aggregation of kraft lignins via electrolyte and nonionic surfactant regulation: stabilization of lignin particles and effects on filtration. Nord. Pulp Pap. Res. J. 32:572-585.

Norgren, M., Lindström, B. (2000) Dissociation of phenolic groups in kraft lignin at elevated temperatures. Holzforschung 54:519-527.

Norgren, M., Mackin, S. (2009) Sulfate and surfactants as boosters of kraft lignin precipitation. Ind. Eng. Chem. Res. 48:5098-5104.

Norgren, M., Edlund, H., Wågberg, L., Lindström, B., Annergren, G. (2001a) Aggregation of kraft lignin derivatives under conditions relevant to the process, part I: phase behaviour. Colloids Surf. A 194:85-96.

Norgren, M., Edlund, H., Nilvebrant, N.-O. (2001b) Physiochemical differences between dissolved and precipitated Kraft lignin fragments as determined by PFG NMR, CZE and quantitative UV spectrophotometry. J. Pulp Pap. Sci. 27:359-363.

Norgren, M., Edlund, H., Wågberg, L. (2002) Aggregation of lignin derivatives under alkaline conditions. Kinetics and aggregate structure. Langmuir 18:2859-2865.

Pandit, A.V., Ranade, V.V. (2016) Chord length distribution to particle size distribution. AIChE J. 62:4215-4228.

Parsons, D.F., Bostrom, M., Lo Nostro, P., Ninham, B.W. (2011) Hofmeister effects: interplay of hydration, nonelectrostatic potentials, and ion size. Phys. Chem. Chem. Phys. 13: 12352-12367.

Schwierz, N., Horinek, D., Netz, R.R. (2013) Anionic and cationic hofmeister effects on hydrophobic and hydrophilic surfaces. Langmuir 29:2602-2614.

Sewring, T., Theliander, H. (2018) A study of kraft lignin acid precipitation in aqueous solutions using focused beam reflectance measurement $\left(\right.$ FBRM $\left.^{\circledR}\right)$. J. Sci. Technol. For. Prod. Process. 6:46-53. 
Sewring, T., Durruty, J., Schneider, L., Schneider, H., Mattsson, T., Theliander, H. (2019) Acid precipitation of kraft lignin from aqueous solutions: the influence of $\mathrm{pH}$, temperature, and xylan. J. Wood Chem. Technol. 39:1-13.

Wynn, E.J.W. (2003) Relationship between particle-size and chordlength distributions in focused beam reflectance measurement: stability of direct inversion and weighting. Powder Technol. 133:125-133.

Zhang, Y., Cremer, P.S. (2009) The inverse and direct Hofmeister series for lysozyme. Proc. Natl. Acad. Sci. USA 106:15249-15253.
Zhu, W., Theliander, H. (2015) Precipitation of lignin from softwood black liquor: an investigation of the equilibrium and molecular properties of lignin. BioResources 10:1696-1714.

Zhu, W., Westman, G., Theliander, H. (2015) The molecular properties and carbohydrate content of lignins precipitated from black liquor. Holzforschung 69:143-152.

Zhu, W., Westman, G., Theliander, H. (2016) Lignin separation from kraft black liquor by combined ultrafiltration and precipitation: a study of solubility of lignin with different molecular properties. Nord. Pulp Pap. Res. J. 31:270-278. 